\title{
Development of a novel fluorescence technique for quantifying the total number of spermatozoa stored in the uterovaginal junction of hens
}

\author{
C. D. McDaniel*, R. K. Bramwell and B. Howarth, $\mathrm{Jr}^{\dagger}$ \\ Department of Poultry Science, The University of Georgia, Athens, GA 30602, USA
}

\begin{abstract}
A technique was developed to determine the total number of spermatozoa stored in the uterovaginal junction of hens. After insemination of spermatozoa treated with the nuclear fluorescent dye bisbenzimide, oviductal tissue was collected from hens and homogenized. Samples of homogenate were dried, and the number of spermatozoa $\mathrm{mm}^{-2}$ was determined with the use of a fluorescence microscope. When spermatozoa were added to excised uterovaginal junction tissue before homogenization, results indicated a $1: 1$ linear relationship between actual numbers of spermatozoa added to the tissue and calculated numbers of spermatozoa added to the tissue. This new technique was used to show that insemination of hens with 25,50 or $100 \times 10^{6}$ spermatozoa resulted in a linear increase in the number of spermatozoa stored in the uterovaginal junction. Insemination of hens with $328 \times 10^{6}$ spermatozoa produced no increase in uterovaginal junction storage of spermatozoa over insemination with $100 \times 10^{6}$ spermatozoa. At the maximum sperm storage tubule filling dose of $100 \times 10^{6}$ spermatozoa, only $0.22 \%$ of the spermatozoa inseminated were found in the uterovaginal junction $24 \mathrm{~h}$ after insemination. Treatment of spermatozoa with bisbenzimide had no detrimental effects on fertility or penetration rates when compared with untreated (control) spermatozoa. However, when spermatozoa were treated with bisbenzimide, hatchability of fertile eggs was reduced. In conclusion, this new fluorescence technique appears to be valuable in determining the total number of spermatozoa stored in the uterovaginal junction of hens.
\end{abstract}

\section{Introduction}

In research on avian fertility it is often necessary to consider sperm-oviduct interactions such as oviductal storage of spermatozoa. The domesticated hen is capable of storing spermatozoa in storage tubules (SST) located in the uterovaginal junction (UVJ) (for review see Bakst et al., 1994).

Van Krey et al. (1971) made histological sections of the uterovaginal junction to determine the number of SST that were full, partially full, or devoid of spermatozoa. However, this technique does not reveal the total number of spermatozoa stored in the uterovaginal junction of the hen. In addition, this technique is very laborious; and during sectioning and histological processing, spermatozoa may be shed from the SST resulting in erroneous estimations.

Brillard and Bakst (1990) have illustrated that brief homogenization of the oviduct of the turkey hen will yield spermatozoa that may be quantified with a haemocytometer. This technique, however, was not tested to determine whether the total number of spermatozoa in the uterovaginal junction of the

\footnotetext{
*Present address: Poultry Science Department, Mississippi State University Box 9665 Mississippi State, MS 39762, USA.

${ }^{\dagger}$ Correspondence.

Received I February 1996.
}

chicken hen could be determined. Some difficulties which may arise when using this procedure to estimate storage of spermatozoa are improper filling of the haemocytometer due to oviductal tissue, problems associated with distinguishing spermatozoa from homogenized oviductal tissue, and short time for sample processing necessitated by enzymatic degradation of spermatozoa.

Bakst (1994) inseminated turkey hens with bisbenzimidetreated spermatozoa to improve visualization of spermatozoa within the SST. Bisbenzimide is a fluorescent dye that binds to the DNA of living cells and fluoresces bright blue at the proper excitatory wavelength (Latt and Stetten, 1976). Bakst (1994) used fluorescence and differential interference contrast microscopy to determine the number of SST that were full, partially full, or empty. Again, this technique does not reveal the total number of spermatozoa residing in the uterovaginal junction.

The aim of the present work was to develop a fluorescence technique for quantifying the total number of spermatozoa stored in the uterovaginal junction of the hen and to determine whether this technique would measure the number of spermatozoa in the uterovaginal junction accurately. Hens were inseminated with increasing doses of spermatozoa to determine whether this technique would reveal significant differences in 


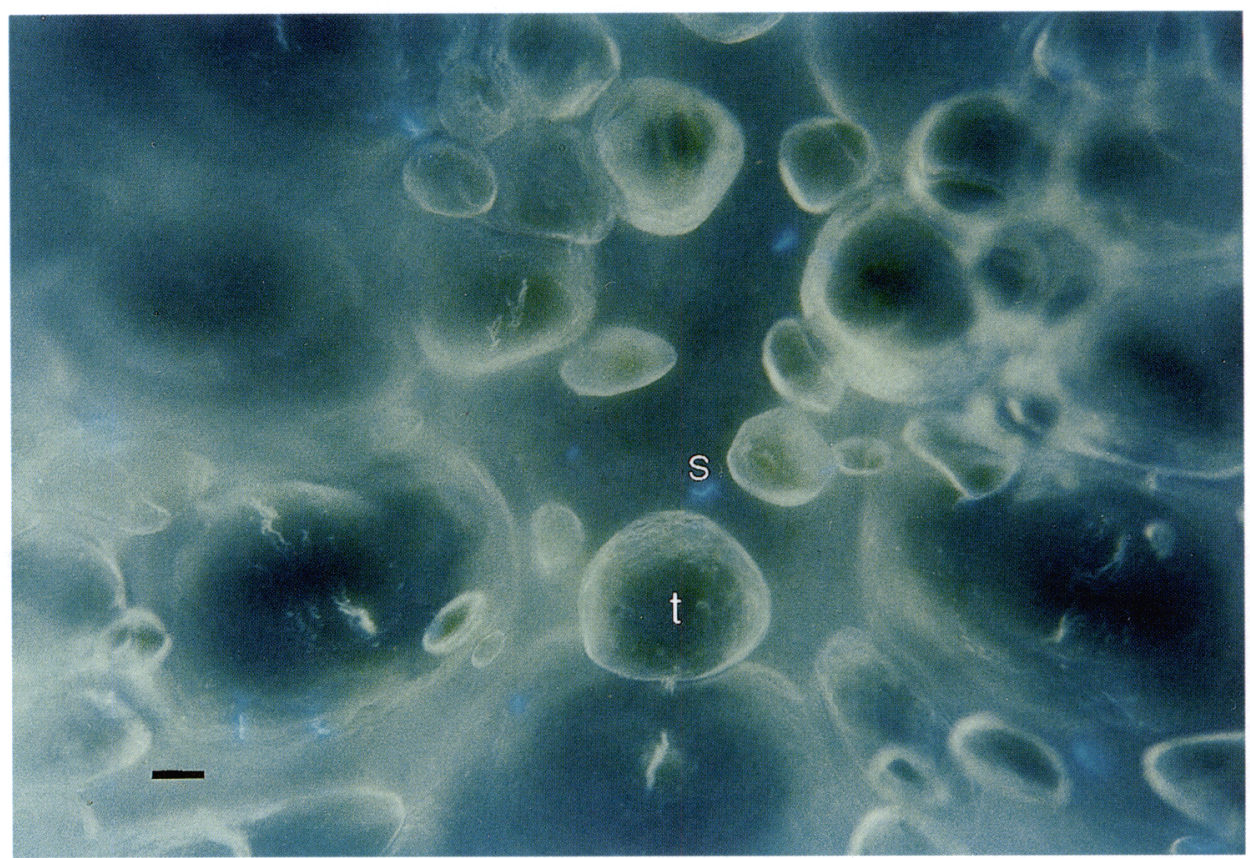

Fig. 1. Photomicrograph illustrating rooster spermatozoa recovered from the uterovaginal junction after homogenization. Spermatozoa were incubated with the fluorescent dye, bisbenzimide, before insemination. The crescent-shaped nuclei of the spermatozoa (s) fluoresce bright blue when exposed to light with a $355 \mathrm{~nm}$ wavelength, whereas oviductal tissue $(t)$ appears white. Scale bar represents $20 \mu \mathrm{m}$.

the number of spermatozoa stored in the uterovaginal junction. The effect of bisbenzimide on spermatozoa storage within the hen's oviduct was assessed by measuring fertility and sperm penetration of ova.

\section{Materials and Methods}

\section{Basic technique}

Semen was collected from 12 50-week-old, broiler breeder males (Gallus domesticus) and diluted 1:I with minimum essential medium (Howarth, 1981). Diluted semen was incubated with bisbenzimide (Hoechst 33342) using a technique similar to that used by Bakst (1994) for turkey semen. Semen was further diluted with two parts of minimum essential medium containing $113 \mu \mathrm{g}$ bisbenzimide $\mathrm{ml}^{-1}$. The diluted spermatozoa were placed on an Adams Nutator (Clay Adams, Parsippany, NJ) and rotated at 24 r.p.m. for $2 \mathrm{~h}$ at room temperature.

Thirty-week-old, virgin White Leghorn hens were maintained in $16 \mathrm{~h}$ of light day ${ }^{-1}$ (lights on at 03:00 h; lights off at 19:00 h). Laying hens were inseminated with bisbenzimidetreated spermatozoa at 14:00 h and killed by cervical dislocation $24 \mathrm{~h}$ after insemination. The abdominal cavity was opened, and a segment of the oviduct from the uterus to the vagina was removed. Connective tissue surrounding the uterovaginal junction was removed with the use of fine scissors and forceps so that the oviductal section was straight. A longitudinal cut was made in the oviduct to expose the lumen and SST. The area containing the SST was excised with the use of a dissecting microscope, and placed in a $20 \mathrm{ml}$ scintillation vial with $0.5 \mathrm{ml}$ of $0.85 \%(\mathrm{w} / \mathrm{v}) \mathrm{NaCl}$. The tissue from the uterovaginal junction was homogenized in the vial at 10000 r.p.m. for 20 s. After homogenization, a $20 \mu \mathrm{l}$ sample of the homogenate was placed on a microscope slide and dried for 5 min under forced air at $55^{\circ} \mathrm{C}$.

The nurnber of spermatozoa in five separate $0.08 \mathrm{~mm}^{2}$ areas of each $20 \mu \mathrm{l}$ drop (average size $=67 \mathrm{~mm}^{2}$ ) was determined with a flucrescence microscope set at an excitatory wavelength of $355 \mathrm{nr}$. Nuclei of the bisbenzimide-treated spermatozoa fluoresce bright blue at this wavelength of light (Fig. I). The five areas counted included one count at the top, bottom, left, right, and centre of each drop. The number of spermatozoa in the entire uterovaginal junction was determined by the following formula: (spermatozoa $\mathrm{mm}^{-2}$ )(total area of drop $\div 20 \mu \mathrm{l}$ ) (total volume of homogenate).

\section{Recovery of spermatozoa}

Increasing concentrations of spermatozoa were added to the excised uterovaginal junction tissue to determine whether this technique could accurately measure the number of spermatozoa residing ir the oviduct. The uterovaginal junction tissue was obtained from seven hens as described previously. Each of these seven oviductal sections was placed in $20 \mathrm{ml}$ scintillation vials with $0.5 \mathrm{ml} 0.85 \%(\mathrm{w} / \mathrm{v}) \mathrm{NaCl}$ containing one of the following amounts of bisbenzimide-treated spermatozoa: $9600,96000,480000,960000,1440000,1920000$, and 2400000 . Successive dilution was used to obtain these concentrations. The concentration of spermatozoa in the original semen sample was determined using the packed cell volume method of Maeza and Buss (1976). 
After addition of spermatozoa to the oviductal tissue, the mixture was homogenized and the number of spermatozoa in each sample determined using the previously described fluorescence method. Data were analysed with linear regression of calculated spermatozoa dose over actual spermatozoa addition dose (Steel and Torrie, 1980). Standard regression produced a linear equation with an intercept not significantly different from zero; therefore, the NOINT (no intercept) option of PROC REG was used to obtain the regression equation (SAS Institute, 1985).

\section{Insemination dose and storage of spermatozoa}

It was reasoned that there must be an insemination dose at which maximum filling of the SST would occur, and that insemination of hens with less than this maximum filling dose should reveal a dosage effect with decreasing spermatozoa storage. Two experiments were conducted to analyse these two concepts.

Experiment 1: maximum filling dose. Semen was incubated with bisbenzimide, and the concentration of spermatozoa was determined using the packed cell volume method. At 14:00 h, five hens were inseminated with $100 \times 10^{\circ}$ spermatozoa, and four hens were inseminated with $328 \times 10^{\circ}$ spermatozoa. Twenty-four hours after insemination, hens were killed, their oviducts were removed, and the number of spermatozoa per uterovaginal junction was determined as described previously. Data were subjected to an ANOVA using a completely randomized design (Steel and Torrie, 1980).

Experiment 2: effect of dosage. On two separate occasions hens were inseminated with 25,50 and $100 \times 10^{6}$ bisbenzimide-treated spermatozoa per $50 \mu \mathrm{l}$ at 14:00 h. Sixty hens were used ( 10 hens per dose per time). Birds were individually caged in replicates of five hens each, such that there were two replicates for each insemination dose. Twentyfour hours after insemination, hens were randomly killed in replicate, and the total number of spermatozoa per uterovaginal junction was determined. The percentage of spermatozoa inseminated that were subsequently stored in the uterovaginal junction was calculated by dividing the total number of spermatozoa per uterovaginal junction by the number of spermatozoa inseminated and multiplying the result by 100 .

Linear regression and ANOVA were used to determine the relationship of insemination dose with spermatozoa storage and percentage of spermatozoa stored. The ANOVA design was a generalized, randomized complete block design with blocks being the two separate times of insemination. Values were transformed by taking the square root of the value plus 0.5 to normalize total sperm storage data. Means were separated using Student-Newman-Keul's sequential range test (Steel and Torrie, 1980).

\section{Effects of bisbenzimide on fertility and penetration of ova}

One hundred and twenty 50-week-old Arbor Acre hens were individually caged and divided into 12 groups of 10 hens each. Hens and roosters were maintained on $16 \mathrm{~h}$ of light

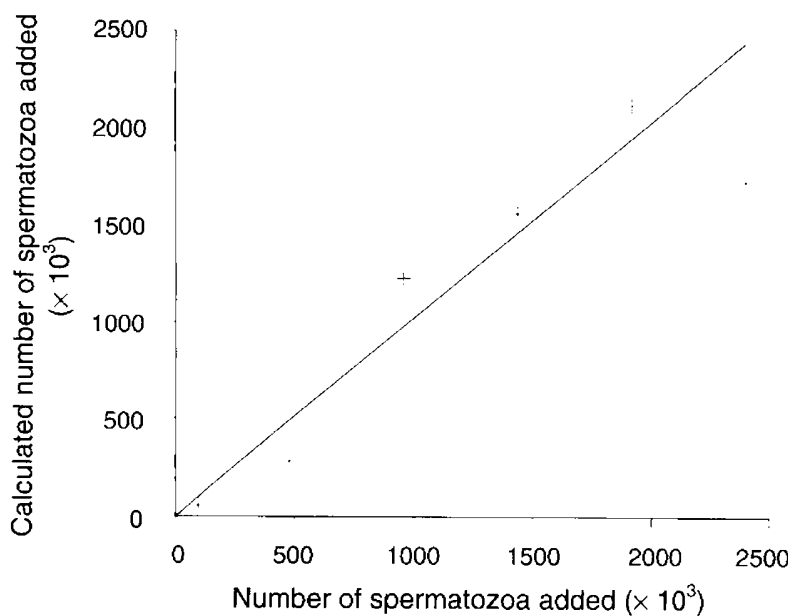

Fig. 2. Recovery of chicken spermatozoa after homogenization of uterovaginal junction tissue in which seven dilutions of spermatozoa ranging from 9600 to 2400000 spermatozoa per $0.5 \mathrm{ml}$ had been added. The line indicates the linear regression of the calculated number of spermatozoa added over the actual number of spermatozoa added $\left(y=1.02 x, P<0.0001\right.$, standard error of the slope $\left.=0.094, r^{2}=0.95\right)$.

day $^{-1}$ (lights on at 05:00 h; lights off at 21:00 h). Semen was collected from 12 roosters, pooled, and divided into two portions. One portion of semen was incubated with bisbenzimide and the other remained unstained. Six groups of hens were inseminated with bisbenzimide-treated spermatozoa, while the other six groups were inseminated with semen that had not been exposed to bisbenzimide. All hens were inseminated at $14: 00 \mathrm{~h}$ with $100 \times 10^{6}$ spermatozoa. Eggs were collected daily for 8 days after insemination and stored in an egg cooler at $13.3^{\circ} \mathrm{C}$. Egg production per hen-day averaged $67 \%$ over the 8 days after insemination, resulting in approximately seven eggs per replicate per day.

The eggs from three of the bisbenzimide groups and three of the control groups were used for fertility and hatchability measurements. The eggs from the remaining groups were used for analysis of penetration of ova by spermatozoa. Candling fertility was determined at 10 days of incubation. All unhatched eggs were opened to determine true fertility.

Penetration of ova by spermatozoa was determined using the method of Bramwell et al. (1995). The perivitelline layer from oviposited eggs was removed, fixed with $20 \%$ formalin, and stained with Schiff's reagent. The number of sperm penetration holes was counted in a $1.35 \mathrm{~mm}^{2}$ area surrounding the germinal disc. Data were subjected to an ANOVA, using a split-plot design in time (day after insemination). Interaction means were separated with Student-Newman-Keul's sequential range test (Steel and Torrie, 1980).

\section{Results}

\section{Recovery of spermatozoa}

A positive linear relationship was found between the calculated number of spermatozoa in the uterovaginal junction and the actual number of spermatozoa added to the oviductal tissue (Fig. 2). With a slope of $1.02 \pm 0.094(P<0.0001)$, the line 


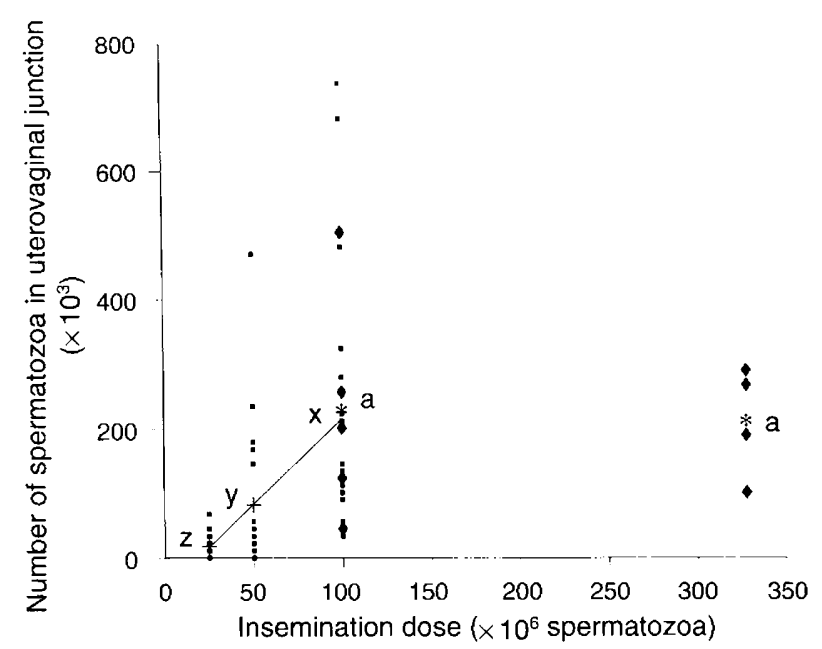

Fig. 3. Relationship between insemination dose and sperm storage in the uterovaginal junction of the chicken's oviduct. In Expt 1 $\left(\bullet=\right.$ results of individual hens; ${ }^{*}=$ treatment means), five hens were inseminated with $100 \times 10^{6}$ bisbenzimide-treated spermatozoa, and four hens were inseminated with $328 \times 10^{6}$ bisbenzimide-treated spermatozoa. In Expt $2(-=$ results of individual hens; $+=$ treatment means), ten hens were inseminated with 25,50 or $100 \times 10^{6}$ bisbenzimide-treated spermatozoa on two separate occasions (two groups of five hens each per dose per time). The line indicates the linear relationship between insemination dose and mean number of spermatozoa stored in the uterovaginal junction during Expt 2 $\left(y=2654 x-49280, P<0.008, r^{2}=0.9998\right)^{a}$ Means for Expt 1 were not significantly different $\left(P>0.9\right.$, SEM $\left.=6.8 \times 10^{4}\right){ }^{x y 2}$ Means for Expt 2 with different superscripts are significantly different $(P<0.0006$ for square root transformed data, nontransformed SEM $=22 \times 10^{4}$ ) Means for Expt 2 represent four groups of five hens each $(n=4)$.

indicates a 1:1 relationship between actual spermatozoa addition and calculated spermatozoa addition. The coefficient of determination $\left(r^{2}\right)$ indicated that $95 \%$ of the variation in calculating the number of spermatozoa in the uterovaginal junction was due to the number of spermatozoa added to the tissue. On average, $94 \%$ of the spermatozoa added to the tissue was recovered after homogenization, as indicated by the short distance of the points from the regression line. The only point not close to the line was at the dose of 2400000 spermatozoa.

At the lowest addition dose of 9600 spermatozoa, only one spermatozoon was counted in all five $0.08 \mathrm{~mm}^{2}$ areas observed. The calculated addition dose for this single spermatozoon was 11200 spermatozoa. Therefore, the detection limit of this technique is approximately 11200 spermatozoa per uterovaginal junction.

\section{Insemination dose and storage of spermatozoa}

Experiment 1: maximum filling dose. When hens were inseminated with $328 \times 10^{6}$ spermatozoa, the number of spermatozoa residing in the uterovaginal junction was not greater than when hens were inseminated with $100 \times 10^{6}$ spermatozoa (Fig. 3).

Experiment 2: effect of dosage. Insemination of hens with $100 \times 10^{6}$ spermatozoa in Expt 2 resulted in the recovery of

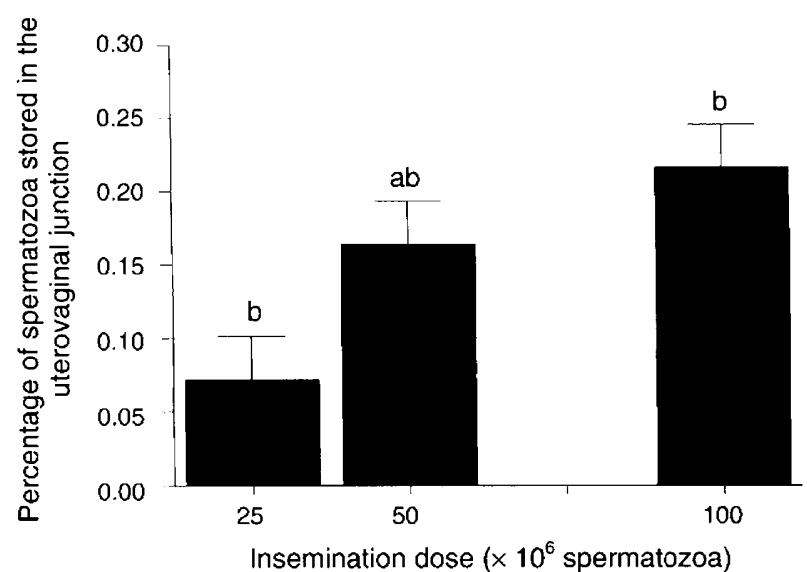

Fig. 4. Relationship between insemination dose and the percentage of spermatozoa stored in the uterovaginal junction within the chicken hen's oviduct. Ten hens were inseminated with either 25,50 or $100 \times 10^{\circ}$ bisbenzimide-treated spermatozoa on two separate occasions (two replicates of five hens each per dose per time). Means with different superscripts are significantly different $(P<0.036$, $\mathrm{SEM}=0.0296$ ). Values represent the mean of four groups of five hens each $(n=4)$.

approximately 216000 spermatozoa from the uterovaginal junction (Fig. 3). This value is very close to the 226000 spermatozoa recovered from the uterovaginal junction when hens were inseminated with $100 \times 10^{6}$ spermatozoa in Expt 1 . In addition the coefficient of variation for the five different areas counted on each slide was only $6.25 \%$. In addition, the coefficient of variation between two samples from each of 15 hens was only $6.32 \%$. However, like most fertility characteristics, the variability between individual hens within a treatment was large as is demonstrated in Fig. 3. Analysis of the treatment means revealed that insemination of hens with 25,50 , and $100 \times 10^{6}$ spermatozoa gave a near perfect positive linear relationship between insemination dose and the number of spermatozoa stored in the uterovaginal junction. In addition, the number of spermatozoa residing in the uterovaginal junction was significantly different at each insemination dose when data were analysed using ANOVA.

The relationship between insemination dose and the percentage of spermatozoa inseminated that were subsequently stored in the uterovaginal junction is shown (Fig. 4). Mean separation procedures reveal that when hens were inseminated with $100 \times 10^{6}$ spermatozoa, the percentage of spermatozoa stored was greater than when hens were inseminated with $25 \times 10^{6}$ spermatozoa. The ANOVA results also show that the percentage of spermatozoa stored when hens were inseminated with $50 \times 10^{6}$ spermatozoa was similar to the percentage of spermatozoa stored when hens were inseminated with 25 or $100 \times 10^{6}$ spermatozoa.

\section{Effects of bisbenzimide on fertility and penetration of ova}

Fertility and the number of spermatozoa penetrating the perivitelline layer were similar when hens were inseminated with control or bisbenzimide-treated spermatozoa (Fig. 5). However, the hatchability of fertile eggs was reduced by 


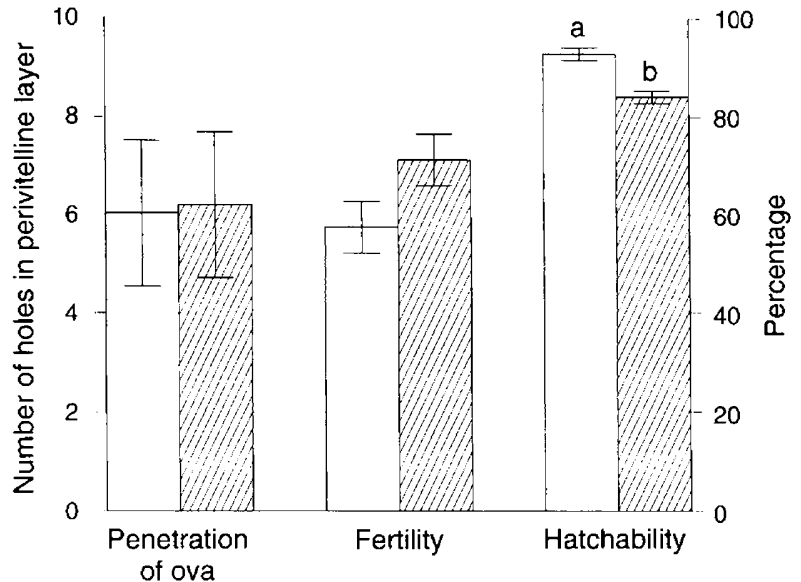

Fig. 5. Penetration of ova, fertility, and hatchability of fertile chicken eggs resulting from insemination with spermatozoa incubated with $(\bigotimes)$ or without $(\square)$ bisbenzimide. Values are expressed as means \pm SEM. Results for hatchability with different letters are significantly different $(P<0.009)$. Penetration $(P>0.94)$ and candling fertility $(P>0.14)$ were similar for control and bisbenzimide-treated spermatozoa. Values represent the replicate means of the second to the eighth day after insemination of three replicates of ten hens each $(n=21)$.

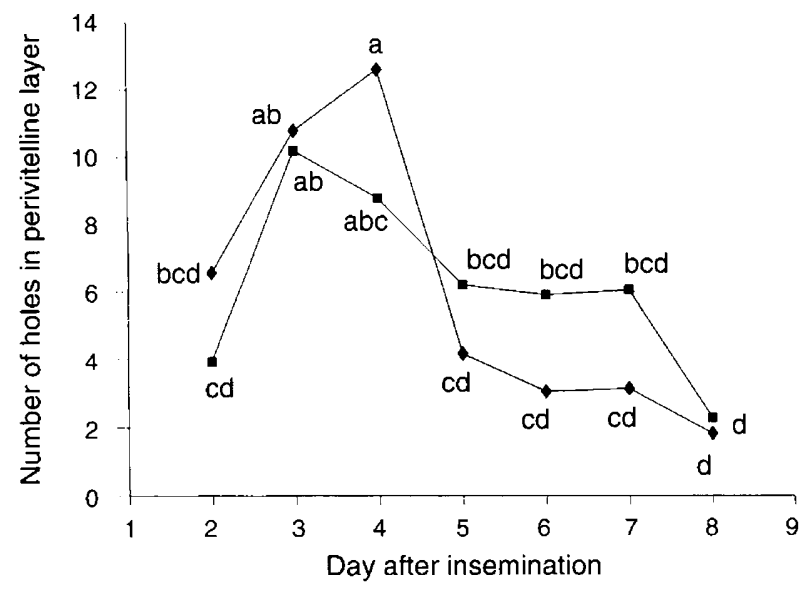

Fig. 6. Penetration of ova for each day after insemination when chicken hens were inseminated with control $(\bullet)$ or bisbenzimidetreated (a) spermatozoa (treatment group by day after insemination interaction, $P<0.07$, SEM $=1.24$ ). Values represent the means of three replicates of ten hens each $(n=3)$. Interaction means with different superscripts differ significantly when analysed with StudentNewman-Keul's sequential range test $(P<0.05)$.

$9 \%$ when hens were inseminated with bisbenzimide-treated spermatozoa when compared with insemination with control spermatozoa.

A significant interaction of treatment by day after insemination was noted for ova penetration (Fig. 6). At every day after insemination, penetration was similar between the two treatment groups. However, from day 2 to day 3 after insemination, there was a significant increase in penetration in hens inseminated with bisbenzimide-treated spermatozoa. No statistical increase in penetration was seen from day 2 to day 3 after insemination in hens inseminated with control spermatozoa. From day 4 to day 5 after insemination, penetration signifi- cantly decreased in hens inseminated with control spermatozoa; the decrease was not significant in hens inseminated with bisbenzimide-treated spermatozoa.

\section{Discussion}

The results presented here indicate that this new fluorescent technique is reliable and capable of measuring as few as 11200 spermatozoa per uterovaginal junction with an average sperm recovery of $94 \%$. Preliminary work by Brillard and Bakst (1990) indicated that $86 \%$ of turkey spermatozoa added to diluent is recovered following homogenization. However, their spermatozoa recovery technique did not include addition of oviductal tissue before homogenization. In addition, Brillard and Bakst (1990) did not indicate the numbers of spermatozoa that were added to the diluent before homogenization. It is possible that oviductal tissue as well as sperm concentration may influence the number of spermatozoa that are homogenized beyond recognition. Indeed, in the current study, sperm recovery did vary with the concentration of spermatozoa added to the oviductal tissue samples.

The present study shows that maximum storage of spermatozoa in the uterovaginal junction occurs with an insemination dose of approximately $100 \times 10^{6}$ spermatozoa. Brillard and McDaniel (1986) have shown that fertility of dwarf broiler breeders does not improve with single insemination doses higher than $125 \times 10^{6}$ spermatozoa, thus indicating a maximum sperm storage for a single insemination. Compton and Van Krey (1979) found no difference in the number of SST containing spermatozoa when hens were inseminated with 0.023 or $0.047 \mathrm{ml}$ of semen and killed $24 \mathrm{~h}$ later. Assuming that $1 \mathrm{ml}$ of semen contains $3.5 \times 10^{9}$ spermatozoa (Johnson, 1986), Compton and Van Krey (1979) inseminated 81 and $165 \times 10^{6}$ spermatozoa. Therefore, the insemination doses of Compton and Van Krey (1979) indicate maximum sperm storage when hens are inseminated with approximately $100 \times 10^{6}$ spermatozoa.

In the current study, insemination doses of less than $100 \times 10^{6}$ spermatozoa resulted in a decrease in the absolute number of spermatozoa stored in the uterovaginal junction. Brillard (1992) has shown that a smaller percentage of SST contain spermatozoa when hens are inseminated with $60 \times 10^{6}$ spermatozoa when compared with insemination with $240 \times 10^{6}$ spermatozoa. When Bramwell et al. (1995) inseminated hens with 25 or $50 \times 10^{6}$ spermatozoa, penetration of ova was significantly reduced compared with insemination of hens with $100 \times 10^{6}$ spermatozoa. The number of spermatozoa stored will directly affect the number of spermatozoa available to penetrate the ovum; thus, the results of Bramwell et al. (1995) may also indicate a reduction in spermatozoa storage at insemination doses lower than $100 \times 10^{6}$ spermatozoa. Indeed, Brillard and Bakst (1990) and Brillard and Antoine (1990) have shown a strong positive correlation between spermatozoa trapped on the perivitelline layer (Wishart, 1987) and spermatozoa retained in the uterovaginal junction of the turkey and chicken hen, respectively.

As in the study by Compton and Van Krey (1979), the hens in the present study were killed $24 \mathrm{~h}$ after insemination when the amount of spermatozoa stored in the SST was determined. 
Brillard (1992) has shown that the number of chicken SST containing spermatozoa reaches a maximum at 1-2 days after insemination. Pierson et al. (1988) found that, in broiler breeder hens, the number of SST containing spermatozoa reaches a maximum $24 \mathrm{~h}$ after insemination. Similar results have been obtained with White Leghorn hens (Schindler et al., 1967). When hens were inseminated with bisbenzimide-treated spermatozoa in the present study, penetration of ova was greatest in eggs laid 3 days after insemination. An egg laid 3 days after insemination would have been exposed to spermatozoa approximately $24 \mathrm{~h}$ earlier, 2 days after insemination. The hens in the current study were killed at 14:00 h on day 1 after insemination; thus, the egg laid on the second day after insemination was usually already past the site of fertilization and beginning calcification within the uterus. Therefore, spermatozoa within the SST at the time of death could have fertilized the ovum which would have been laid 3 days after insemination. Therefore, in the present study the SST were probably at their maximum fill-rate for a single insemination.

When hens were inseminated with 25, 50, 100, and $328 \times 10^{6}$ spermatozoa, approximately $0.07,0.16,0.22$, and $0.06 \%$ of the spermatozoa inseminated were subsequently stored in the uterovaginal junction, respectively. The increasing percentage of spermatozoa stored with increasing insemination dose (up to $328 \times 10^{6}$ spermatozoa) may involve selection of spermatozoa within the vagina (for review see Bakst et al., 1994). Perhaps, the close proximity of spermatozoa at higher concentrations results in a greater percentage entering the SST. Head-to-head agglutination is seen once chicken spermatozoa enter the SST (Van Krey et al., 1981). Apparently, only a few selected spermatozoa enter the uterovaginal junction and SST. Brillard (1993) suggested that about $0.9 \%$ of inseminated spermatozoa are stored in the SST of the broiler breeder hen. In addition, Brillard and Bakst (1990) estimated that less than 1\% of spermatozoa inseminated into turkey hens was stored in the SST when hens were inseminated with $200 \times 10^{6}$ spermatozoa. It is understandable that such a small percentage of spermatozoa is stored in the SST, considering approximately $87 \%$ of inseminated spermatozoa are evacuated from the turkey hen's cloaca within $1 \mathrm{~h}$ of artificial insemination (Howarth, 1971).

Unlike previous studies that evaluated oviductal storage of spermatozoa, the current work involved treating spermatozoa with bisbenzimide. There is a lack of information concerning the effects of bisbenzimide on chicken fertility. Therefore, it was questioned whether treatment of spermatozoa with this fluorescent dye would alter subsequent oviductal spermatozoa storage. However, treatment of broiler breeder spermatozoa with bisbenzimide does not appear to reduce oviductal storage of spermatozoa. Hens inseminated with bisbenzimide-treated spermatozoa laid eggs with fertility and penetration rates comparable to those of hens inseminated with untreated (control) spermatozoa. In addition, penetration rates and fertility were similar between the two treatment groups during each of 8 days after insemination. However, hatchability of fertile eggs was depressed when hens were inseminated with bisbenzimide-treated spermatozoa. As bisbenzimide binds to DNA within the sperm nucleus, it is possible that genetic alteration of the spermatozoon may have affected embryonic development. Bakst (1994) found that, in turkeys, insemination with bisbenzimide-treated spermatozoa produced fewer fertile eggs than did insemination with control spermatozoa; and, although a reduction was seen in the hatchability of fertile eggs, the difference was not statistically significant. It is possible that turkey spermatozoa are more sensitive to treatment with bisbenzimide than chicken spermatozoa are.

This new fluorescent spermatozoa technique provides many advantages over previous methods for estimating oviductal storage of spermatozoa. Tedious histological work is not required with this new technique as is required with the technique of Van Krey et al. (197I). Because the complete uterovaginal junction is used with this technique, the entire number of spermatozoa residing in the lumen of the uterovaginal junction and stored in the SST is determined. Unlike the technique of Brillard and Bakst (1990) for determining oviductal sperm storage in turkey hens, this new technique eliminates the use of a haemocytometer which may clog with oviductal tissue resulting in improper filling. Staining of spermatozoa with bisbenzimide eliminates the likelihood of recording oviductal tissue as spermatozoa. In addition, with the fluorescent spermatozoa technique, homogenate samples are dried and may be analysed at a later time.

The primary disadvantage with this new technique is that hens must be killed to obtain oviductal tissue. Therefore, repeated measurements of spermatozoa storage over time cannot be conducted on the same animal. It is possible that bisbenzimide may leach out of spermatozoa that are stored in the oviduct for an extended period of time. Therefore, this technique may be of only limited use in some studies involving long-term oviductal storage of spermatozoa. However, in the present study, no decrease in spermatozoa fluorescence, as determined both visually and with a fluorometer, was observed after $48 \mathrm{~h}$ of incubation at $39^{\circ} \mathrm{C}$ in a dye-free diluent (minimum essential medium). Even in investigations of long-term sperm storage, this new technique may be valuable in demonstrating relative differences in oviductal sperm storage between treatments. Recently, data were presented in abstract form where McDaniel et al. (1995) used this novel fluorescence technique to reveal that sperm storage in the uterovaginal junction is decreased when the male broiler breeder is heat-stressed before semen collection and artificial insemination. Therefore, the results of this study show that this new fluorescence technique could be very useful in determining the total number of spermatozoa residing in the uterovaginal junction.

The authors would like to acknowledge J. Mathis for the many hours of technical assistance she provided in this project. The authors would also like to thank $M$. Bakst for generously supplying the bisbenzimide stock solution. This research was supported by State and Hatch funds allocated to the Georgia Agricultural Experiment Station of the University of Georgia.

\section{References}

Bakst MR (1994) Fate of fluorescent stained sperm following insemination: new light on oviducal sperm transport and storage in the turkey Biology of Reproduction $\mathbf{5 0}$ 987-992

Bakst MR, Wishart G and Brillard JP (1994) Oviducal sperm selection, transport, and storage in poultry Poultry Science Reviews 5 117-143

Bramwell RK, Marks HL and Howarth B (1995) Quantitative determination of sperm penetration of the perivitelline layer of the hen's ovum as assessed on oviposited eggs. Poultry Science 74 1875-1883 
Brillard JP (1992) Factors affecting oviductal sperm-storage in domestic fowl following artificial insemination Animal Reproduction Science 27 247-256

Brillard JP (1993) Sperm storage and transport following natural mating and artificial insemination Poultry Science 72 923-928.

Brillard JP and Antoine $\mathrm{H}$ (1990) Storage of sperm in the uterovaginal junction and its incidence on the number of spermatozoa present in the perivitelline layer of hen's eggs British Poultry Science 31 635-644

Brillard JP and Bakst MR (1990) Quantification of spermatozoa in the spermstorage tubules of turkey hens and the relation to sperm numbers in the perivitelline layer of eggs Biology of Reproduction 43 271-275

Brillard JP and McDaniel GR (1986) Influence of spermatozoa numbers and insemination frequency on fertility in dwarf broiler breeder hens Poultry Science $65 \quad 2330-2334$

Compton MM and Van Krey HP (1979) A histological examination of the uterovaginal sperm storage glands in the domestic hen following an insemination with variable semen dosages Poultry Science 58 478-480

Howarth B, Jr (197I) Transport of spermatozoa in the reproductive tract of turkey hens Poultry Science 50 84-89

Howarth B (1981) Preservation of the fertilizing capacity of cock semen incubated in vitro at $41^{\circ} \mathrm{C}$ Poultry Science $601075-1078$

Johnson AL (1986) Reproduction in the male. In Avian Physiology pp 432-45I Ed. PD Sturkie. Springer-Verlag, New York

Latt SA and Stetten G (1976) Spectral studies on 33258 Hoechst and related bisbenzimidazole dyes useful for fluorescent detection of deoxyribonucleic acid synthesis Journal of Histochemistry and Cytochemistry $2424-33$
McDaniel CD, Bramwell RK and Howarth B, Jr (1995) The male contribution to broiler breeder heat stress infertility as determined by sperm-egg penetration and sperm storage within the hen's oviduct Poultry Science 74 (Supplement 1) 71

Maeza AS and Buss EG (1976) Sperm concentration and sperm numbers as related to fertility in chickens Poultry Science 552059 (Abstract)

Pierson EEM, McDaniel GR and Krista LM (1988) Relationship between fertility duration and in vivo sperm storage in broiler breeder hens British Poultry Science 29 199-203

SAS Institute (1985) SAS User's Guide: Statistics Version 5. SAS Institute Inc., Carey, NC

Schindler H, Ben-David E, Hurwitz S and Kempenich O (1967) The relation of spermatozoa to the glandular tissue in the storage sites of the hen oviduct Poultry Science 46 1462-1471

Steel RGD and Torrie JH (1980) Principles and Procedures of Statistics. A Biometrical Approach (2nd Edn) McGraw-Hill Book Co, Inc, New York, NY

Van Krey HP, Balander RJ and Compton MM (1981) Storage and evacuation of spermatozoa from the uterovaginal sperm-host glands in domestic fowl Poultry Science 43 132-139

Van Krey HP, Siegel PB and Leighton AT, Jr (1971) Repeatability estimates and quantification of uterovaginal sperm-host gland numbers and population patterns Biology of Reproduction 4 31-34

Wishart GJ (1987) Regulation of the length of the fertile period in the domestic fowl by numbers of oviductal spermatozoa, as reflected by those trapped in laid eggs Journal of Reproduction and Fertility 80 493-498 